\title{
Appendix 2: Affirmative and Sceptic Briefs and Rebuttals
}

\section{(C) 2012 Mark Widdowson, Katie Banks, Julia McLeod and Cholena Mountain}

Note

The arguments presented here are made to facilitate the analysis of change in this case through the presentation of contrasting views; they are not necessarily the personal views of the authors.

\section{Affirmative Brief \\ Positive Evidence}

The purpose of this analysis is firstly to draw conclusions about two questions:

\section{Client changed substantially over therapy}

2. Therapy contributed substantially to those changes.

It is our conclusion that the client changed substantially over the course of therapy and that therapy contributed substantially to his changes. Furthermore we conclude there were no other major factors which contributed to or caused the client's changes.

There are a number of types of evidence which can be used to support these conclusions. The types of evidence are:

1. changes in stable problems

2. retrospective attribution

3. outcome to process mapping

4. links between client reliable gains in the $P Q$ scores and significant within therapy events

\section{5. within therapy process-outcome correlation.}

For this affirmative case to be plausible and robust, the causal inference provided by direct evidence
Table B1: Summary of Outcome Data

\begin{tabular}{llll} 
& $\begin{array}{l}\text { Beck } \\
\text { Depression } \\
\text { Inventory-II }\end{array}$ & CORE-OM & $\begin{array}{l}\text { Personal } \\
\text { Questionnaire } \\
\text { (mean score) }\end{array}$ \\
\hline $\begin{array}{l}\text { Clinical cut- } \\
\text { off }\end{array}$ & 10 & 10 & 3.00 \\
\hline $\begin{array}{l}\text { Caseness } \\
\text { cut-off }\end{array}$ & 16 & 15 & 3.5 \\
\hline $\begin{array}{l}\text { Reliable } \\
\text { Change }\end{array}$ & $\mathbf{5 . 7 8}$ & 4.8 & $\mathbf{0 . 5 3}$ \\
\begin{tabular}{l} 
Index \\
\hline Pre-Therapy
\end{tabular} & 35 & 21.7 & $\mathbf{5 . 8 3}$ \\
\hline Session 8 & 32 & 20.2 & $4.71(+)$ \\
\hline Session 16 & $20(+)$ & $12.9(++)$ & $2.71(++)$ \\
\hline $\begin{array}{l}\text { 1 month } \\
\text { Follow-up }\end{array}$ & $10(++)$ & $5.2(++)$ & $2.57(++)$ \\
\hline $\begin{array}{l}\text { 3 month } \\
\text { Follow-up }\end{array}$ & $13(++)$ & $11.9(++)$ & $2.28(++)$ \\
\hline
\end{tabular}

must be demonstrated in at least two of these five types of evidence.

1. Change in stable problems

In his Personal questionnaire Peter described a number of issues he wanted to resolve in therapy (Table B2), all of which were long-standing problems for him of at least six years in duration. At the end of therapy, and sustained at follow up, Peter had achieved positive change with each problem he had identified at the beginning of therapy. This can be taken as an indication that Peter had resolved or made significant changes in problems which had been long standing concerns of his. From Change Interview data, Peter reported that these changes were all very unlikely to have occurred without therapy. 


\begin{tabular}{|c|c|c|c|c|c|c|}
\hline & $\begin{array}{l}\text { Duration of } \\
\text { the problem }\end{array}$ & Pre & Mid & End & $\begin{array}{l}1 \\
\text { month } \\
\text { Follow } \\
\text { up }\end{array}$ & $\begin{array}{l}3 \\
\text { month } \\
\text { Follow } \\
\text { up } \\
\end{array}$ \\
\hline 1.I don't know what makes me tick & $>10$ years & 7 & 4 & 4 & 4 & 3 \\
\hline 2. My body clock is very disrupted & $6-10$ years & 6 & 6 & 4 & 4 & 5 \\
\hline 3. My mood is inconsistent & $>10$ years & 5 & 4 & 3 & 2 & 3 \\
\hline 4. I don't feel OK about myself & $>10$ years & 6 & 6 & 4 & 4 & 1 \\
\hline 5. I am not sure how my family relationships impact on me & $>10$ years & 7 & 7 & 2 & 2 & 2 \\
\hline 6. Disconnected from my feelings & $>10$ years & 7 & 4 & 1 & 1 & 1 \\
\hline $\begin{array}{l}\text { 7. Problems with memory \& concentration [item } 7 \text { added by } \\
\text { client at session 2] }\end{array}$ & $6-10$ years & 5 & 2 & 1 & 1 & 1 \\
\hline
\end{tabular}

Peter identified seven problems he wished to address in therapy. At the end of therapy Peter's PQ scores had moved into non-clinical range of distress on four of these problems. The remaining three problems all showed a significant improvement of at least two points by the end of therapy and maintained at follow-up.

Our analysis of Peter's weekly PQ scores suggests he experienced a gradual movement in the direction of positive change. There were two temporary increases in Peter's PQ scores, at session 8 and session 13, which reflected temporary increase in distress. We consider the increase at session 8 to be linked to external factors, and the increase at session 13 to be linked to the 'script backlash process' the therapist describes. Both increases in distress were temporary and both were followed by marked improvement suggesting that Peter had experienced some rather significant change or resolution in engaging with these issues. We also note that Peter continued to maintain, and even make further changes in 6 of his $P Q$ items after the period of research therapy was concluded. It is possible these changes may have been sustained and continued as a result of his 'maintenance therapy'. Nevertheless, we note that considerable change occurred to longstanding problems. His mean PQ score at the beginning of therapy was 5.83 indicating that his problems were bothering him 'considerably' to 'very considerably'. His mean PQ score had reduced at the end of therapy to 2.71 indicating his problems were bothering him 'very little' to 'little' and therefore indicating that he had moved out of the clinical range of distress on the problems he identified. This mean score was again reduced by the second follow-up to 2.27. This was a drop on mean PQ scores throughout his therapy of 3.56 points.

We consider these changes to be substantial, given that Peter identified five of his problems as being over ten years in duration, and the remaining two as being between six and ten years in duration.

Peter's CORE-OM scores indicated a movement from a level of moderate distress and impairment into the non- clinical range. Similarly, his scores from the BDI-II indicated movement from severe depression into a nonclinical range.

Comparison of Peter's PQ, CORE-10 and BDI-II scores all indicate movement out of clinical levels of distress to non-clinical levels across all three measures, adding weight to the argument that Peter has experienced clinically significant levels of change.

Of the five overall changes Peter identified in his followup change interview, he rated one of these changes as 'moderately' important, two as 'very' important, and two as 'extremely' important.

2. Retrospective attribution of changes to therapy In Peter's follow-up interviews he identified that all of the changes he made would have been unlikely to have occurred without therapy.

Data from change interview provides evidence that the client attributes his change process to therapy. In particular:

C3: the client reports: "possibly one of the most positive experiences... it's made a huge difference to me"

C7: "it's very strange but over time it's been one of the things that I look forward... and for me has made a huge personal difference".

C81: the client reports; "Therapy has been the means for change."

In Peter's Change Interview he identified five major changes. He stated that he was surprised by all five of these changes, and that he felt that these changes were very unlikely to have come about without therapy.

3. Outcome to process mapping

Outcome-to-process mapping refers to the correspondence between specific events in therapy and overall changes experienced by the client as a result of 
Table B3: Outcome to Process Mapping

\begin{tabular}{|c|c|}
\hline $\begin{array}{l}\text { Outcome } \\
\text { (changes described } \\
\text { at Post-therapy } \\
\text { follow up interview) }\end{array}$ & $\begin{array}{l}\text { Process } \\
\text { (HAT Descriptions) }\end{array}$ \\
\hline $\begin{array}{l}\text { A shift in } \\
\text { perspective from } \\
\text { 'life is shit' to } \\
\text { 'actually, maybe } \\
\text { l'm not viewing } \\
\text { things clearly' }\end{array}$ & $\begin{array}{l}\text { Session 8: } \\
\text { Reassurance of the validity and } \\
\text { correctness of my criticisms of both my } \\
\text { family and society, and of my response to } \\
\text { these. The reassurance helped me } \\
\text { maintain objectivity and perspective. } \\
\text { (Helpfulness - 9) } \\
\text { Session 16: } \\
\text { Realising that the negative part of my } \\
\text { personality has a block on my positive } \\
\text { feelings. Knowing this, I can work against it. } \\
\text { (Helpfulness - 9) }\end{array}$ \\
\hline $\begin{array}{l}\text { Awareness of } \\
\text { these reinforcing } \\
\text { patterns and how I } \\
\text { get into them }\end{array}$ & $\begin{array}{l}\text { Session 5: } \\
\text { Realising that my family hasn't conveyed } \\
\text { the feeling of their unconditional support } \\
\text { and love. Helps me to understand what } \\
\text { makes me tick. (Helpfulness - 8) } \\
\text { Discussion of my withdrawn nature. } \\
\text { (Helpfulness - 7) } \\
\text { Session 10: } \\
\text { Admitting my conception of who and how } \\
\text { I am, my drive for literal altruism at } \\
\text { personal cost. It's an expression of who I } \\
\text { am, and an acknowledgement of my } \\
\text { 'uncomfortable sanity'. It's the basis for } \\
\text { who I will choose to be. (Helpfulness - 9) } \\
\text { Session 12: } \\
\text { Recognizing that strokes containing the } \\
\text { criticism of 'you're inadequate' set off my } \\
\text { depression. Helps me to look for, identify } \\
\text { and reject these strokes. } \\
\text { (Helpfulness - 8) } \\
\text { Session 16: } \\
\text { Realising that the negative part of my } \\
\text { feelings. Knowing this, I can work against it. } \\
\text { (Helpfulness - 9) }\end{array}$ \\
\hline $\begin{array}{l}\text { A sense of hope } \\
\text { and possibilities for } \\
\text { change }\end{array}$ & $\begin{array}{l}\text { Session 7: } \\
\text { Elaboration of my emotional needs } \\
\text { regarding fulfilment in life. Felt like it laid } \\
\text { groundwork for later sessions. } \\
\text { (Helpfulness - 7) } \\
\text { Session 11: } \\
\text { Achieving the goal I had for the session- } \\
\text { finding an experiential approach that will } \\
\text { let me find a method of coping with } \\
\text { emotions. It's inherently good, as it will }\end{array}$ \\
\hline
\end{tabular}

be useful, and it's satisfying to achieve. (Helpfulness-9)

Session 14:

The discussion; it feels like groundwork for future resolution. I got a feeling of progress. (Helpfulness - 8)

\section{Session 16:}

Realising that the negative part of my personality has a block on my positive feelings. Knowing this, I can work against it

\section{Starting to interpret Session 8:} things differently e.g. not expecting a fall, not expecting bad things to happen

Reassurance of the validity and correctness of my criticisms of both my family and society, and of my response to these. The reassurance helped me maintain objectivity and perspective. (Helpfulness - 9)

Bringing the elements of my family dynamics into focus. (Helpfulness - 7)

\section{Session 12:}

Recognizing that strokes containing the criticism of 'you're inadequate' set off my depression. Helps me to look for, identify and reject these strokes. (Helpfulness - 8)

\section{Session 16:}

Realising that the negative part of my personality has a block on my positive feelings. Knowing this, I can work against it. (Helpfulness - 9)

Changes in how I feel in myself and in how I interact with othersinterpersonal changes

\section{Session 7:}

Elaboration of my emotional needs regarding fulfilment in life. Felt like it laid groundwork for later sessions. (Helpfulness - 7)

\section{Session 13:}

A deconstruction of the probably psychological reasons behind my feelings. Understanding. (Helpfulness - 7)

\section{Session 11:}

Achieving the goal I had for the sessionfinding an experiential approach that will let me find a method of coping with emotions. It's inherently good, as it will be useful, and it's satisfying to achieve. (Helpfulness - 9)

\section{Session 15:}

Recognition of a deficiency in my interpersonal skills and the suggestion of a new approach. It gives me a way forward, to express myself with the confidence that I might be understood. An instant- "eureka!"(Helpfulness - 9) 
therapy. The 'Helpful Aspects of Therapy' form (HAT) was completed by the client at the end of each session and provides us with regular and immediate reports of what Peter found helpful in his therapy sessions. Details of helpful aspects of sessions which Peter highlighted as most helpful (a rating of $>7$ ) have been linked here to the changes Peter identified in his follow-up change interview.

We note that the changes Peter identified in his HAT forms were most frequently connected to increased self-awareness and interpersonal changes. Peter also identified helpful aspects of therapy as involving identifying and changing reinforcing patterns, and changes in emotion/ emotional expressiveness and self-acceptance. These changes are consistent with a TA approach to therapy which places joint emphasis on internal (intrapsychic change) and on interpersonal changes. The aim of TA therapy is for the client to move to an 'I'm OK-You're OK' life position indicating self-acceptance and respectful and growthful relating to others. We also note the aspects of affective change link to the therapist's use of deconfusion and the changes in identifying and changing self-reinforcing patterns lins to the therapist's use of transactions, strokes, games, rackets and scripts. All of the changes indicated here are also congruent with the 12 point plan/TA psychotherapy formulation for depression identified in this research.

\section{Event-Shift Sequences (links between} reliable gains in the $P Q$ scores and significant within therapy events)

Although Peter's mean $\mathrm{PQ}$ scores tended to show gradual and consistent change over the course of the therapy, no significant items (where there had been a reduction in mean score by at least 1 point) were identified which could indicate specific event-shift sequences relating to the use of specific techniques and substantial improvement on PQ scores.

Analysis of the therapist notes, when compared to the data on Peter's HAT forms, indicate direct correlations to the therapist's interventions (events) and the aspects Peter found most helpful (shifts).

\section{Table B4: Client Comments related to Therapist Interventions}

\begin{tabular}{|c|c|c|c|}
\hline $\begin{array}{l}\text { Sessio } \\
\text { n no }\end{array}$ & Helpful aspect/What Made it Helpful & Rating & Therapist Interventions \\
\hline 1 & $\begin{array}{l}\text { When the therapist said 'the word that comes to mind is crushed' it } \\
\text { put a lot of my feelings into perspective and put my problem into } \\
\text { stark relief in a very raw, but helpful way. It made me admit/ } \\
\text { acknowledge something I couldn't see on my own }\end{array}$ & 8 & $\begin{array}{l}\text { The therapist uses the interventions of } \\
\text { "interpretation" and "specification" which are } \\
\text { specific to TA theory and there is a direct } \\
\text { correlation with the client's rating and comments }\end{array}$ \\
\hline \multirow[t]{2}{*}{2} & $\begin{array}{l}\text { Admitting/ explaining my perspective and intentions in the bullying } \\
\text { incident. l'd never admitted it before, never felt that l'd be believed } \\
\text { and something old and sore and forgotten brought to the surface. }\end{array}$ & 7.5 & $\begin{array}{l}\text { Explanation of the PAC model is significant to } \\
\text { the client's rating and the Structural Analysis } \\
\text { enabled the client's expression of a shameful } \\
\text { past experience. }\end{array}$ \\
\hline & Parent/Adult/Child model explanation & 7 & \\
\hline \multirow[t]{2}{*}{5} & $\begin{array}{l}\text { Realising that my family hasn't conveyed the feeling of their unconditional } \\
\text { support and love. Helps me to understand what makes me tick. }\end{array}$ & 8 & $\begin{array}{l}\text { The therapist explains the concept of strokes } \\
\text { and the client is able to make the link to what is } \\
\text { missing in his relationship with his family. }\end{array}$ \\
\hline & Discussion of my withdrawn nature & 7 & \\
\hline \multirow[t]{2}{*}{6} & $\begin{array}{l}\text { Expressing/ understanding my fundamental drive of anger and } \\
\text { awareness of the break that makes it: self-knowledge }\end{array}$ & 9 & $\begin{array}{l}\text { The therapist's use of structural analysis and } \\
\text { deconfusion work enabled the client to } \\
\text { express/understand his drive of anger }\end{array}$ \\
\hline & $\begin{array}{l}\text { Improving my therapist's understanding of me, it's nice to be } \\
\text { understood }\end{array}$ & 6 & \\
\hline 7 & $\begin{array}{l}\text { Elaboration of my emotional needs regarding fulfilment in life. Felt } \\
\text { like it laid groundwork for later sessions. }\end{array}$ & 7 & $\begin{array}{l}\text { Therapist use of Inquiry, Attunement and } \\
\text { Involvement, exploration of existential issues } \\
\text { and rupture/ repair models }\end{array}$ \\
\hline 8 & $\begin{array}{l}\text { Reassurance of the validity and correctness of my criticisms of both } \\
\text { my family and society, and of my response to these. The } \\
\text { reassurance helped me maintain objectivity and perspective. }\end{array}$ & 9 & $\begin{array}{l}\text { The therapist's use of the TA theories of } \\
\text { contracting, life positions and strokes has a direct } \\
\text { correlation with the client's ratings and comments }\end{array}$ \\
\hline & Bringing the elements of my family dynamics into focus & 7 & \\
\hline
\end{tabular}



relational needs. Therapist supporting client with on-going rejection of negative strokes and the impact they have on his self-esteem and feelings of inadequacy

10 Admitting my conception of who and how I am, my drive for literal altruism at personal cost. It's an expression of who I am, and an acknowledgement of my 'uncomfortable sanity'. It's the basis for who I will choose to be

11 Achieving the goal I had for the session- finding an experiential approach that will let me find a method of coping with emotions. It's inherently good, as it will be useful, and it's satisfying to achieve.

12 Recognizing that strokes containing the criticism of 'you're inadequate' set off my depression. Helps me to look for, identify and reject these strokes

$9 \quad$ Existential exploration, game and script analysis

A deconsturtion of the orobablv pschological reasons behind my

13 A deconstruction of the probably psychological reasons behind my feelings. Understanding.

Therapist use of empathic approach and deconfusion process
8 The client links the session to the theory of Strokes. In addition the therapist used transactions, game theory and heighteners to aid the client's move towards a redecision

\begin{tabular}{|c|c|c|c|}
\hline & feelings. Understanding. & & $\begin{array}{l}\text { enabled the client to further understanding and } \\
\text { awareness }\end{array}$ \\
\hline 14 & $\begin{array}{l}\text { The discussion; it feels like groundwork for future resolution. I got a } \\
\text { feeling of progress }\end{array}$ & 8 & $\begin{array}{l}\text { The session continued with further work on } \\
\text { internal processes and ego state dialogue } \\
\text { which the client felt was progress. }\end{array}$ \\
\hline 15 & $\begin{array}{l}\text { Recognition of a deficiency in my interpersonal skills and the } \\
\text { suggestion of a new approach. It gives me a way forward, to express } \\
\text { myself with the confidence that I might be understood. An instant } \\
\text { "eureka!" } \\
\text { Clarification of my position in my family }\end{array}$ & 9 & $\begin{array}{l}\text { This session shows a direct correlation between } \\
\text { the therapist's use of the theories of } \\
\text { intrapsychic and interpersonal processes } \\
\text { (demonstrated using Classical TA theories of } \\
\text { transactions etc) and the client's ratings after } \\
\text { the session. }\end{array}$ \\
\hline 16 & $\begin{array}{l}\text { Realising that the negative part of my personality has a block on my } \\
\text { positive feelings. Knowing this, I can work against it }\end{array}$ & 9 & $\begin{array}{l}\text { The therapist uses impasse clarification and } \\
\text { permissions to further the therapy work. The } \\
\text { client makes the link between the therapy } \\
\text { session and his greater level of self-awareness } \\
\text { as per his ratings after the session }\end{array}$ \\
\hline
\end{tabular}

\section{Session-by-session process-outcome} correlation

The affirmative analysis team could not identify any major session-by-session process-outcome correlations.

\section{Conclusion}

We put forward the evidence that four out of five criteria have been met, namely:

- Peter demonstrated considerable change in stable problems.

- Peter attributed these changes to therapy.

- There is a correlation between the therapy process and the overall changes Peter made as a result of therapy.

- There are plausible links between the therapist's interventions, events in therapy which Peter found to be significant and his overall change.
We conclude from this that Peter changed considerably during the period of the therapy and that these changes occurred as a result of therapy.

\section{Sceptic Case}

1. The apparent changes are negative (i.e. involve deterioration) or irrelevant (i.e. involve unimportant or trivial variables).

Although analysis of the changes Peter experienced using data from quantitative measures suggest positive change, and that he identified these changes as important, there were several points in the therapy where he reported deterioration. Also, data from the second follow-up with Peter suggest some deterioration from their previous improvement, which could indicate that the client's changes were not stable or long-lasting. One item on Peter's $P Q$ form relating to a disrupted body clock showed fluctuation throughout 
therapy, and was still in the clinical range at the end of therapy.

At the end of therapy, although Peter's BDI-II score demonstrated improvement, it was still in the clinical range of scores. These scores continued to improve beyond the period of the research, although as he continued to have 'maintenance therapy', it is difficult to determine whether this continued improvement was as a result of therapy or of a trend towards a 'selfcorrecting process' and part of the natural course of his depression or spontaneous remission.

Furthermore, although at the end of therapy and at the second follow-up, the client's CORE scores and BDI-II scores were below the 'caseness cut-off' level, they were still in the sub-clinical range, which could indicate only temporary improvement and the presence of subclinical levels of distress which would return to levels of 'diagnosable severity' once the therapy had finished.

2. The apparent changes are due to statistical artefacts or random error, including measurement error, experiment-wise error from using multiple change measures, or regression to the mean.

We note that Peter's changes using quantitative measures showed improvement greater than criteria levels for Reliable Change Index improvement. Although multiple measures were used throughout the research, there does not always appear to be consistency between Peter's PQ scores and his BDI-II and CORE scores, particularly in the first half of the therapy.

Furthermore, we note that other than the initial pre-test scores, there are no multiple pre-test scores available so we cannot rule out the possibility of regression to the mean. As Peter met $\mathrm{RCl}$ criteria on all three measures used, we do not consider 'experiment-wise error' (chance occurrence) to be a factor.

3. The apparent changes reflect relational artefacts such as global "hello-goodbye" effects on the part of a client expressing his or her liking for the therapist, wanting to make the therapist feel good, or trying to justify his or her ending therapy. It is possible that relational artefacts have influenced Peter's scores and reporting on his therapy. For instance, Peter actively sought out the therapist as someone he believed to be the best therapist available for him, and his reports of the therapist are very positive and do not include any negative description of the therapist or of disappointment in the therapy process (despite some issues not being addressed in the therapy) [see change interview, particularly mother's death issues].

His description of his therapist in his change interview is extremely positive, despite the therapist reporting several instances of 'alliance rupture' and of Peter being angry with his therapist in sessions. The client's description of the therapy process tended to focus on the therapist's positive relational skills rather than particular interventions or specific therapist technical skills.

Furthermore, in his change interview, Peter describes his internal change process without reference to the therapist or to specific procedures or interventions which occurred within the therapy. We note that Peter clearly liked his therapist and therefore consider relational artefacts may be relevant in this case.

It was difficult to determine whether the client was being influenced by specific TA interventions, or simply through the chance to talk to someone he trusted and liked. We particularly note that Peter did not make use of 'TA language' in his change interview, and did not mention specific therapist interventions, or events within therapy, but rather discussed a broad 'relational ambience'.

4. The apparent changes are due to cultural or personal expectancy artefacts; that is, expectations or "scripts" for change in therapy.

Peter often used 'psychological language' to describe his change process which might suggest he is basing his change on expectancy of a 'script' for change in therapy (for example, C36 and parts of C37, C38, C39 and C42). We note that sometimes the language he used in his descriptions of his change process was quite 'intellectual' and referred to more general and perhaps even vague changes, as opposed to specific and concrete changes.

In particular we note that Peter did not make substantial external life changes during therapy, or in the period of follow-up. There was also some distancing, and generalised language in his description, for example; C7 'Cause talking to someone frankly and openly and to have them concerned about your mental well-being is very alien. It's alien to people in general'.

In C3, Peter says 'I think that I might actually be fully cured and be able to do all the things I actually want to do in life and for me that's golden.' Later in the interview he appears to contradict this slightly by saying in C4 'I do occasionally have a day when it's bit like a relapse', and in C18 he describes some feelings of anxiety and nervousness and that 'I don't feel that I'm fully recovered just yet'. In C96 he also describes not having done much work in therapy about his feelings regarding his mother's death.

Due to his use of 'psychological language', and the slight inconsistencies in his reporting, we consider there is some evidence to suggest the client is attributing his change to therapy due to personal and cultural expectancy artefacts. 
5. There is credible improvement, but it involves a temporary initial state of distress or dysfunction reverting to normal baseline via corrective or self-limiting processes unrelated to therapy.

Although we note that credible improvement occurred throughout the period Peter engaged in the research, we cannot rule out that any changes that Peter experienced were not changes associated with the natural course of major depressive disorder or related to spontaneous remission.

6. There is credible improvement, but it is due to extra-therapy life events, such as changes in relationships or work.

There were no significant life changes, or changes in external circumstances that occurred during Peter's therapy. The changes that did occur were changes which he initiated (such as changes in behaviour and in how he related to others) and were changes which he attributed to therapy. Nevertheless, we note that the client did not make significant life changes throughout the course of therapy which we feel might undermine the argument that he had made substantial and credible improvement as a result of therapy.

7. There is credible improvement, but it is due to unidirectional psychobiological processes, such as psychopharmacological medications, herbal remedies, or recovery of hormonal balance following biological insult.

We conclude that there is no evidence of the existence of any new psychobiological factors which might have influenced Peter's change process.

8. There is credible improvement but it is due to the reactive effects of being in research.

It is possible that participation in the research gave Peter a sense of contributing to a 'greater good' and doing something meaningful which had a direct impact on his mood, and in particular counteracted his sense of inadequacy. His participation may have provided him with a sense of altruism which might have provided him with a temporary increase in his self-esteem.

\section{Rebuttals}

Note

During the period when the affirmative and sceptic cases were being prepared, further follow-up data was obtained. This data has been added to Table B1 and is shown in the six-month follow-up row in Table B5.
Table B5: Updated Summary of Outcome Data

\begin{tabular}{llll} 
& $\begin{array}{l}\text { Beck } \\
\text { Depression } \\
\text { Inventory-II }\end{array}$ & CORE-OM & $\begin{array}{l}\text { Personal } \\
\text { Questionnaire } \\
\text { (mean score) }\end{array}$ \\
\hline $\begin{array}{l}\text { Clinical cut- } \\
\text { off }\end{array}$ & 10 & 10 & 3.00 \\
\hline $\begin{array}{l}\text { Caseness } \\
\text { cut-off }\end{array}$ & 16 & 15 & 3.5 \\
\hline $\begin{array}{l}\text { Reliable } \\
\text { Change } \\
\text { Index }\end{array}$ & $\mathbf{5 . 7 8}$ & 4.8 & $\mathbf{0 . 5 3}$ \\
\hline Pre-Therapy & 35 & 21.7 & 5.83 \\
\hline Session 8 & 32 & 20.2 & $4.71(+)$ \\
\hline Session 16 & $20(+)$ & $12.9(++)$ & $2.71(++)$ \\
\hline $\begin{array}{l}\text { 1 month } \\
\text { Follow-up }\end{array}$ & $10(++)$ & $5.2(++)$ & $2.57(++)$ \\
\hline $\begin{array}{l}\text { 3 month } \\
\text { Follow-up }\end{array}$ & $13(++)$ & $11.9(++)$ & $2.28(++)$ \\
\hline $\begin{array}{l}6 \text { month } \\
\text { Follow-up }\end{array}$ & $8(++)$ & $5(++)$ & $2.21(++)$ \\
\hline
\end{tabular}

Affirmative rebuttal to sceptic case

Note

The arguments presented here are made to facilitate the analysis of change in this case through the presentation of contrasting views; they are not necessarily the personal views of the authors.

The rebuttals presented here are concerned with items 1-6 from the sceptic case.

1. The apparent changes are negative (i.e., involve deterioration) or irrelevant (i.e., involve unimportant or trivial variables).

The client's scores on all three quantitative outcome measures had improved considerably by the end of therapy and the client had achieved reliable change on all three measures.

Although there was some deterioration on CORE10/CORE-OM and BDI-II scores between the first and second follow-up measurements, these still remained below the 'caseness' level and within sub-clinical ranges. Whilst the deterioration which occurred in the client's CORE scores did meet criteria for reliable change, the deterioration on the client's BDI-II scores did not. In spite of this deterioration on CORE and BDIII measures, the client's mean $\mathrm{PQ}$ scores continued to show improvement, indicating that the issues the client originally came to therapy to address had not returned. The client experienced a drop of 3 points on the mean scores of the $P Q$ which would suggest major and clinically significant change to the client's presenting 
problems which was maintained after the end of therapy. At the six-month follow-up, Peter's BDI-II and CORE scores had returned to below the clinical cut-off, which may suggest that the increase in distress measured at the three-month follow-up represented a period of temporary distress or difficulty or a response to a significant stressor. It is possible that Peter had developed sufficient internal resources and had experienced sufficient personal change during the course of his therapy to enable him to overcome this period of distress effectively without experiencing relapse.

The sceptic team point to small changes on the PQ item 'My body clock is very disrupted'. Although there is insufficient data to fully explain the slower rate of change on this item, the item has nevertheless demonstrated reliable change from pre-therapy measures. It is possible that this item may relate to a 'characterological symptom' (Kopta et al, 1994). In their study, Kopta and his associates identified several symptoms relating to sleep which were slow to respond to psychotherapy. In particular the symptom 'trouble falling asleep' was estimated to require more than 104 sessions for $50 \%$ of clients to have achieved clinically significant change. As such, and in relation to this present study it is perhaps not surprising that 16 sessions of therapy did not result in clinically significant change for this item, and therefore the argument that minimal change on this item suggests the therapy was ineffective is something of a flawed argument. In relation to extra-therapy factors, as the client is not in employment, it is possible that there is not the same imperative to maintain a regular sleep routine.

Finally, in response to the sceptic team's query regarding whether this issue was central to Peter's experience of depression, we note that in his follow up interview the client indicates that he did not think this was a central issue in his experience of depression (see extracts below).

The sceptic team also highlight a relatively small degree of change in the PQ item 'My mood is inconsistent'. Again, this item demonstrated reliable change and clinically significant change which was maintained throughout the follow up period. It is possible that this item did not change as dramatically as some of the other items due to the client experiencing greater reactivity in his feelings as the therapy proceeded. Given that the client was disconnected from his feelings prior to therapy, this might be an expected and positive change as a result of therapy. This view seems to be strengthened by the client referencing experiencing positive feelings in the transcript extract below:

C104: '(on discussing 'my body clock is disrupted)... I said way back that it was probably going to be one of the last things to change as I think it's a symptom of other stuff essentially. My mood is inconsistent. l'd say my mood is much more consistent now. I don't have it plummeting down the same way as I did. Ok, occasionally
I might have a bad or off day but it doesn't feel anywhere near as frequent. Now I am getting the reverse. Now I'm getting days that are good, just actually genuinely 'oh god I'm happy to be alive', which l'd never have thought of at the start. That one is much less of a problem. '

C109: (on discussing whether he would change the $P Q$ items) 'The only thing I can think of conceptually is conceptually reorder them which I can do in hindsight, which I couldn't do at the time. Which is some of these are causes of other ones like 'my body clock is very disrupted'. That's a product of a lot of other stuff going on there. I don't think it's an inherent problem in and of itself.'

\section{The apparent changes reflect relational} artefacts such as global "hello-goodbye" effects on the part of a client expressing his or her liking for the therapist, wanting to make the therapist feel good, or trying to justify his or her ending therapy. Rather than seeing the client's positive attitude to his therapist as an aspect of relational artefacts we would expect and indeed look for this positive attitude towards the therapist at this early stage in the work (16 sessions) when working relationally with a client like Peter. The therapist states earlier in the case study that he/she tends to work more relationally (Section 3 Therapist's comments) and as such would be likely to have worked with introjective transference (Hargaden and Sills, 2002) and that the client experienced this as a meeting of their relational needs (Erskine and Trautmann, 1996) (see also the narrative of the therapy process where the therapist identified working with relational needs). Given Peter's history (for example, his mother's death, experience of criticism and few personal relationships) it is possible that holding the therapist in an idealising transference may actually be evidence to support the argument that the client experienced positive change. We also note the finding from many previous research studies which highlights the importance of the therapeutic relationship as the most important factor in the change process, and as such, this present case is congruent with such findings.

The narrative of the case study suggests that at several points the client and therapist experienced difficulties and relationship ruptures. It would appear that these were successfully resolved, and again, it is perhaps only to be expected that a client who had been through such rupture repairs would emphasise the relational skills of their therapist. Perhaps this might be even more so for a client who had a history characterised by relational misattunement?

Suggestions that the work is tinged by an overly positive glow are not supported by statements by the client that he felt he still had work to do, and that the therapy did not go into great detail in certain areas (for example exploring his feelings about his mother's death). Indeed it could be argued that these client statements actually add credibility to claims that the therapy was highly 
effective and appropriate to the client's needs by offering a balanced, rather than solely positive view.

Furthermore, rather than seeing the client's descriptions of the therapy as being focused on the therapist's relational qualities, we consider this to be evidence of the therapist's technical skill in applying technique flexibly and unobtrusively. Again, in light of the therapist's identified 'relational' approach, we would expect these features to be more significant in the change process as opposed to more specific techniques and procedures.

Nevertheless, it is clear that not only did the therapist use TA theory to guide their thinking and intervention, but that they actively discussed TA theory with their client. In the HAT forms, the client specifically mentioned the concept of strokes and ego states. In the follow up interview, the client uses the phrase 'consensual reality', a phrase used in the cathexis approach to TA. We also consider that the client's descriptions of his changes correspond to specific aspects of TA theory; his 'change in perspective' and changes in expectations both suggest a change in his life script, his increased awareness of his reinforcing patterns suggests change in relation to his life script, rackets and games, and changes in how he interacts with others suggest changes in his ego states, transaction patterns, stroking patterns, games, rackets and life script. All of these aspects of TA theory were discussed in the therapist's notes and the case narrative, so we feel that the client's changes can be attributed to active and specific application of TA theory and method, in addition to more general 'therapeutic common factors'.

3. The apparent changes are due to cultural or personal expectancy artefacts; that is, expectations or "scripts" for change in therapy.

We feel that the arguments that the client's changes were associated with expectancy are undermined by several lines of evidence. Firstly, the client reported deterioration at several points in therapy, and indeed his CORE score at the second follow up period shows some deterioration, which suggest that rather than reflecting expectancy, these scores reflect an honest engagement with the research process and selfappraisal of his situation. In the follow up interview, the client identified all of his major changes as 'surprising' and unexpected which suggests that self-suggestion, hope and expectancy were not features which would account for the client's changes.

The client also describes a series of plausible changes, which, as stated above, appear to correlate with the mechanisms and theories used in TA therapy. Furthermore, the client describes the core changes which he experienced and changes which followed on from these. He also specified the links between these changes and describes the change process.
It is also possible that a depressed client who had engaged in previous therapy which had not resulted in change would enter a second period of therapy with little sense of hope for change. This possibility may also have been true for Peter, as he stated a significant change for him was an increased sense of hope for the future, suggesting that the therapy had impacted on his feelings of hopelessness and despondency.

Whilst we note that the client at times used 'psychological language' to describe his change process, we consider that this is to be expected given his previous experience of therapy and his interest in psychology. Again, in line with our previous argument, some of the language he used in both the HAT forms and the change interview suggest he was actively using TA concepts to understand his internal process, his change process and his therapy.

Finally, the contradictions put forward by the sceptic case regarding the quote from the change interview statement $\mathrm{C} 3$ are in our view statements that are misunderstood. What Peter refers to is a hope that he might be cured at some point in the future. He states: "For the first time, obviously l'm not finished my longterm therapy yet but I feel like I might actually be able to be fully cured and not have relapses". This statement cited as a change due to expectancy artefacts, is a quotation which we feel is not true to the intended meaning stated by Peter in C3.

4. There is credible improvement, but it involves a temporary initial state of distress or dysfunction reverting to normal baseline via corrective or self-limiting processes unrelated to therapy.

Peter reported a baseline stability in the intensity and duration of his problems (as evidenced by his previous diagnosis of depression). He had previously tried medication and some short-term therapy which had resulted in minimal change and had not significantly impacted on his depressive symptoms or process. Both of these factors would suggest that his problems were not a temporary state of distress which would pass naturally.

Whilst Peter did show some improvement on some scales post-therapy, we suggest that it is possible that the therapy had triggered a series of on-going internal changes for Peter which continued after the therapy had concluded.

Furthermore, Peter attributed the changes he made due to the therapy he received as part of this research project. For these reasons, we conclude that Peter's improvement cannot be attributed to an easing of a state of acute distress, a reverting to a 'normal baseline', or a selflimiting process and his changes came about as a result of his therapy. 
5. There is credible improvement, but it is due to extra-therapy life events, such as changes in relationships or work.

There were no significant life changes, or changes in external circumstances that occurred during Peter's therapy. The changes that did occur for Peter included changes in his self-concept and changes in his behaviour and in how he related to others, all of which were changes which he attributed to therapy. As these changes cannot be attributed to major external changes in his life and personal circumstances, we conclude that these changes, which the client considered to be important, occurred as a direct result of his therapy, and were not as a result of other extra-therapy events.

The primary changes which the client reported are indeed changes in perspective (frame of reference), changes in his self-concept and changes in how he relates to others. We consider that such changes are a central part of the depression recovery process and in some ways perhaps more important than major changes in behaviour or life-changes. Also, if the client had made significant changes, it could be possible that a circular argument could be created which attributed positive change to these 'extra therapy events'. We also note the client's previous engagement in CBT and ineffectiveness of behavioural activation approaches in producing symptomatic relief.

Nevertheless, we do note that there is evidence of behavioural change. In session 3 the therapist successfully encouraged the client to engage in more social contact, and also in session 15 Peter described initiating social contact which had gone well, indicating a shift to a more pro-active social stance. We think that for a depressed client with poor self-esteem, low confidence and who is socially isolated that this is a significant change in behaviour.

Also, in the follow-up interview the client made various comments that he considered that the therapy had involved significant ground work which he would use to implement substantial life-changes at a later date after a period of consolidation. Given the relatively short length of time of the therapy, we think this is entirely reasonable, and given the severity of his original symptoms, is entirely appropriate.

Finally, we think there is a need to consider Peter's role as a part-time carer. It is possible that this provides very real limits on what is practical and possible for him in terms of major external life change. Additionally, we also note that Peter is unemployed, and as such has limited financial resources available which may also add to the limits of what is practical and possible for him in relation to major life changes.

\section{Sceptic Rebuttal to Affirmative Case}

The affirmative discussion of the question of the client's disruptive body clock reflects a careful and valuable further analysis of the data, and seems convincing.

However, the affirmative rebuttal does not effectively challenge the key sceptic position: at the end of therapy, the client experienced a temporary feeling of well-being, which arose from regular contact with his therapist, but did not exhibit any substantial shift in his relationships with other people, or in his everyday life as a whole. As a result, as the meetings with the therapist tailed off, his symptoms gradually returned. This analysis is reinforced by the fact that the Change Interview was conducted largely from an 'affirmative' position - the interviewer was not active enough in seeking information that would be relevant to the sceptic case.

We also note that in the third (six month) follow-up measurements Peter demonstrated an improvement in his scores from those at the second (three month) follow-up, with reliable change occurring on his CORE scores. No further information is provided to account for either the increase in scores at the three-month follow-up or the reduction in scores at the six-month follow-up. This fluctuation may indicate that the impact of extra-therapy factors on Peter's symptoms is greater than has been indicated previously, and/or that his symptoms are more reactive and responsive to external stressors than suggested in the case report, and that changes he has made have been due to extratherapy factors, instead of due to therapy.

From a sceptic position, several of the lines of argument made by the affirmative team are just not relevant. The research task is to determine whether a good outcome occurred - arguments that rely on an analysis of the therapy process as being constructive, or on what might be expected in a certain number of sessions, are of theoretical interest but do not directly address the question of whether a good outcome was observed.

The sceptic view is that Peter was helped, in terms of learning about himself and gaining insight, but that these are not sufficient to sustain a claim that clinically significant and lasting change took place in his functioning in the world. 